\title{
KOMUNIKASI LINGKUNGAN SEBAGAI UPAYA PENCEGAHAN KERUSAKAN LINGKUNGAN KAWASAN WISATA (STUDI DESKRIPTIF PADA PEMERINTAH KABUPATEN PESISIR SELATAN DI KAWASAN WISATA MANDEH)
}

\author{
Aulira M. Tan, Sarmiati, Elfitra \\ Program Studi Magister Ilmu Komunikasi. Fakultas Ilmu Sosial dan Ilmu Politik, Universitas Andalas, \\ Jl. Situjuh no.1, Jati, Padang. \\ Email: auliramtan@gmail.com
}

\begin{abstract}
Enviromental problem that occur currently are increasingly damaging to the nature in tourist area of Mandeh by forest burning, mangroves hoarding, and the contamination that happens to the sea. Therefore, it needs a serious effort to increase the concern of people around towards living environment to avoid damage to the quality of tourism. This research using qualitative method by descriptive case study to get the enviromental communication goals from Pesisir Selatan Enviromental Services toward the enviromental damage in tourist area of Mandeh. The need of enviromental communication as an effort to communicate enviromental sustainability, the researcher using communication planning theory which can help to build the awareness and concern of the society or industry in the enviromental surroundings. The result of this research shows that DLH (Pesisir Selatan enviromental services) using communication planning during their activity according to the 8 steps of enviromental communication, but it has not been done massively. Besides through a direct activity with the society such as socialization, training, coaching, forum group discussion and enviromental community, DLH also using media to share the information to the society such as using radio, SPM TV, the billboard, sign of prohibition and online media. Another finding obtained through communication planning analyze from DLH is they know the behaviour of society, knowing the potential of enviromental impact, and providing the options and direction, it turns out among them there is the existence of word of mouth in society that happens within society to share information that given by government.
\end{abstract}

Keywords: enviromental communication, prevention of enviromental damage, tourist area.

ABSTRAK

Permasalahan lingkungan yang terjadi saat ini sudah semakin merusak alam di Kawasan Wisata Mandeh dengan pembakaran hutan, penimbunan mangrove dan pencemaran air laut. Dengan demikian, diperlukan upaya serius dalam meningkatkan kepedulian masyarakat pada lingkungan hidup untuk menghindari terjadinya kerusakan kualitas lingkungan pariwisata. Penelitian ini dengan menggunakan metode kualitatif studi kasus deskriptif untuk mendapatkan tujuan komunikasi lingkungan dan kendala dari Dinas Lingkungan Hidup (DLH) Kabupaten Pesisir Selatan pada kerusakan lingkungan di Kawasan Wisata Mandeh. Perlunya komunikasi lingkungan sebagai upaya mengomunikasikan kelestarian lingkungan hidup, sehingga peneliti menggunakan teori perencanaan komunikasi yang dapat 


\begin{abstract}
membangun kesadaran dan kepedulian masyarakat/industri pada lingkungan hidup. Hasil penelitian menunjukkan bahwa DLH menggunakan perencanaan komunikasi dalam kegiatan yang dilakukan sesuai dengan 8 langkah komunikasi lingkungan, namun belum dilakukan secara masif. Selain melalui kegiatan langsung dengan masyarakat seperti sosialisasi, pelatihan, pembinaan, FGD dan komunitas lingkungan, DLH juga menggunakan media untuk menyampaikan informasi pada masyarakat luas seperti radio, SPM TV, baliho, plang larangan dan media online. Temuan yang didapatkan melalui analisis perencanaan komunikasi dari DLH adalah mereka mengetahui kebiasaan masyarakat, lalu mengetahui potensi dampak lingkungan, selanjutnya memberikan opsi dan arahan, ternyata diantara itu terdapat komunikasi dari mulut ke mulut yang terjadi dalam masyarakat untuk menyampaikan informasi yang diberikan oleh pemerintah.
\end{abstract}

Kata Kunci: Komunikasi Lingkungan, Pencegahan Kerusakan Lingkungan, Kawasan Wisata.

\section{PENDAHULUAN}

Pariwisata di Indonesia menjadi kunci utama dalam meningkatan pendapatan sebuah daerah, jika berbicara mengenai pariwisata tentunya tidak terlepas dari alam yang ada di sekitarnya, karena pariwisata tidak akan berarti jika alam yang dimilikinya tidak mendukung keindahan yang ditawarkan. Alam jika dikelola dengan baik tentu akan menghasilkan bentuk positif untuk makhluk hidup yang lainnya, namun apa yang terjadi jika tempat pariwisata yang sudah dipromosikan dengan begitu luar biasanya baik melalui media, media sosial, dan alat lainnya menjadi rusak. Sedangkan, daerah tentunya sudah sangat bangga memiliki tempat wisata yang elok seperti Kawasan Wisata Mandeh.

Kerusakan alam pada pariwisata tentunya akan merusak identitas tempat tersebut di mata para wisatawan, apalagi kerusakan tidak berada di satu titik saja, melainkan di lima titik dalam berbagai kerusakan. Hal ini tentu menjadi tantangan tersendiri bagi Pemerintah Kabupaten dalam menyikapi, memperbaiki dan mencegah terjadinya hal yang tidak diinginkan terkait dengan reputasi Kawasan Wisata Mandeh.

Pengrusakan di Kawasan Mandeh bukan hanya bicara hutan lindung, akan tetapi persoalan penguasaan lahan serta melakukan pembangunan tanpa memperhitungkan lingkungan. Keindahan kawasan wisata Mandeh saat ini harus dinodai dengan banyaknya penebangan hutan di bukitbukit sekitaran Kawasan Wisata Mandeh, di tebang dan di bakar tentu saja akan sangat merusak banyak ekosistem dan hilangnya kawasan wisata yang hijau. Selain itu taman hutan mangrove yang menjadi daya tarik terindah di Kawasan Wisata Mandeh untuk sekian hektar sudah ditebang oleh beberapa oknum yang menjadikan tempat tersebut sebagai ladang usaha dengan membangun resort atau sejenisnya untuk kepentingan pribadi. Ada juga yang menebang mangrove guna membuat sampan, rumah dan lainnya, karena bagi masyarakat mangrove dikenal sebagai kayu yang kuat. Hal ini tentu akan memperburuk situasi lingkungan yang ada, hutan mangrove sangat dibutuhkan oleh sebuah pantai untuk melindungi garis pantai dari abrasi dan meredam gelombang besar termasuk bencana 
alam gelombang besar seperti tsunami. Hutan mangrove juga menjadi habitat satwa langka, sejak hutan mangrove di Mandeh sudah dirusak sejumlah biota lainnya sudah berangsur punah dan hilang, karena setiap harinya memancing ikan tak satu ekor pun ikan asli yang bersarang di mangrove tersebut ada lagi. Selain itu isu lingkungan lain di Kawasan Wisata Mandeh adalah pengeboman ikan yang mengakibatkan kerusakan karang dan keruhnya air laut. Tidak hanya itu hal ini juga dapat membuat punah populasi ikan sekitar karena bom dapat membunuh semua bibit ikan. Kerusakan karang juga diakibatkan karena pengambilan karang untuk cenderamata, sehingga harus dibudidayakan kembali.

Pengrusakan lingkungan di Kawasan Wisata Mandeh ini tidak terlepas dari urusan izin lingkungan yang tidak dipatuhi sesuai dengan aturan pemerintah yaitu izin AMDAL atau analisis dampak lingkungan yaitu bentuk analisis yang menentukan objek dapat mencemari lingkungan sekitar atau tidak, jika berdampak merusak maka akan dilakukan pencegahan, hal ini merujuk pada buku Soemarwoto (2014:34) berfungsi sebagai petunjuk untuk letak pembangunan yang layak disuatu wilayah.

Komunikasi lingkungan untuk menyampaikan maksud hingga terjadi penerimaan pesan dari seseorang atau sekelompok orang kepada orang lain baik pribadi, kelompok, publik atau secara massal berkaitan dengan situasi dan kondisi lingkungan, baik lingkungan fisik maupun sosial. Dengan begitu tujuan yang diharapkan oleh penulis dari penelitian ini adalah mendeskripsikan proses komunikasi lingkungan yang diterapkan Pemkab dan memberikan saran dan ide baru untuk Dinas Lingkungan Hidup.

Pada penelitian ini penulis menggunakan konsep dari penelitian terdahulu Wahyudin yang memberikan point penting dari proses komunikasi lingkungan yaitu 8 langkah komunikasi lingkungan, dimana hal ini dapat digunakan dalam situasi pemerintahan daerah. Selain itu penggunaan teori yang berhubungan erat dengan proses adalah perencanaan untuk mendapatkan tujuan dari proses tersebut, sehingga penelitian ini sangat cocok dengan Teori Perencanaan Komunikasi dari Budyatna karena sangat berhubungan erat dengan tujuan yang ingin dicapai oleh penulis yaitu ingin mengetahui komunikasi lingkungan seperti apa yang dilakukan Dinas Lingkungan Hidup Pesisir Selatan dalam upaya pencegahan kerusakan lingkungan di Kawasan Wisata Mandeh. Komunikasi lingkungan yang dimaksud adalah seperti apa perencanaan, pelaksanaan dan pengevaluasian yang dilakukan untuk mencapai kesepahaman bersama dari elemen komunikasi.

\section{METODE PENELITIAN}

Penelitian menggunakan paradigma konstruktivis merujuk pada Creswell (2013: 11) dengan metode penelitian kualitatif deskriptif menggunakan pendekatan studi kasus untuk mendeskripsikan atau mengkonstruksi wawancara-wawancara mendalam terhadap subjek penelitian sehingga dapat memberikan gambaran yang jelas mengenai komunikasi lingkungan pada Pemerintah Kabupaten menangani komunikasi lingkungan pada Kawasan Wisata Mandeh saat ini. Dengan pengumpulan data melalui wawancara semi- 
terstruktur dan observasi terus terang. Selain itu juga menggunakan observasi terus terang dengan mendatangi langsung subjek penelitian dan mendapatkan 5 titik kerusakan di Kawasan Wisata Mandeh saat ini, hal ini juga dilengkapi dengan data dokumentasi merujuk pada buku (Sugiyono, 2017: 104).

Subjek dan objek penelitian yaitu DLH dan Kawasan Wisata Mandeh, dimana yang dilihat adalah komunikasi lingkungan DLH. Informan ditentukan dengan purposive sampling, merujuk pada buku (Afrizal, 2014:140-141) yang mengatakan langkah ini memberikan kriteria yang sudah ditentukan yaitu Dinas Lingkungan hidup Pesisir Selatan. Terdapat empat orang informan yang sudah ditentukan kriterianya, umumnya adalah dari DLH. Mereka yang berperan dalam memberikan komunikasi pada masyarakat dan investor di Kawasan Wisata Mandeh. Selain itu juga sebagai validitas data peneliti menggunakan triangulasi sumber merujuk pada (Bungin, 2014: 264), yaitu dari Wali Nagari Sungai Nyalo Mudiak Aia Tarusan yang menerima langsung program komunikasi lingkungan dari DLH untuk masyarakat di nagarinya.

Menggunakan teknik analisis data dari Miles dan Huberman dalam Sugiyono (2017:134-135), yaitu melakukan redukasi data yaitu proses pemilihan dan penyederhanaan data mentah yang didapatkan (Emzir, 2010: 129). Selanjutnya pengajian data dan penarikan kesimpulan yang didalamnya berisi rangkuman dari setiap pertanyaan.

\section{HASIL DAN PEMBAHASAN}

Peneliti menemukan bahwa DLH sudah melakukan berbagai upaya dalam komunikasi untuk menjelaskan mengenai dampak lingkungan, namun pemerintah sendiri masih belum mampu memberikan aturan dan sanksi tegas pada pada pelanggar yang mengakibatkan kerusakan lingkungan di Kawasan Wisata Mandeh.

Beberapa kegiatan komunikasi lingkungan yang dilakukan oleh DLH berdasarkan perencanaan yang diterapkan adalah sosialisasi yang dilakukan dengan teknik maraton, FGD dengan pihak akademis dan penggiat lingkungan dari universitas, pembinaan pada masyarakat, pelatihan, dan pembentukan komunitas lingkungan. Selain itu DLH tidak hanya menggunakan cara langsung berkomunikasi dengan masyarakat dan investor, kecanggihan teknologi komunikasi saat ini juga dimanfaatkan semaksimal mungkin oleh DLH, diantaranya yaitu penyuarakan menganai upaya pencegahan kerusakan lingkungan melalui SPM TV yaitu siaran TV milik kabupaten sendiri, lalu siaran radio kabupaten, Baliho menjaga lingkungan yang dipasang pada tempat strategis sehingga mudah dilihat, plang pelarangan proyek yang diberhentikan kegiatannya karena melanggar zonasi dan tanpa izin lingkungan, pemberitaan di koran cetak dan online berdasarkan statement Bupati yang sudah koordinasi dengan DLH, memberikan pengarahan menjaga lingkungan yang benar melalui facebook dan website DLH, serta broadcast dari grup WhatsApp sehingga mudah untuk saling membagikan.

Peneliti penggunakan konsep komunikasi lingkungan dari Cox dalam Yenrizal (2017:9) mengatakan bahwa komunikasi lingkungan adalah sarana konstitutif dan pragmatis bagi pemahaman manusia dengan lingkungan 
serta hubungan manusia dengan alam. Hal ini adalah media simbolis yang digunakan dalam menkonstruksi masalah-masalah lingkungan dan menegosiasikan respon yang berbeda dalam masyarakat. Dengan kata lain komunikasi lingkungan digunakan untuk menciptakan kesepahaman mengenai permasalahan lingkungan.

Penelitian tentang komunikasi lingkungan tidak jauh dari sebuah perencanaan komunikasi yang harus dimiliki oleh Dinas Lingkungan Hidup, mereka melakukan komunikasi yang efektif pada masyarakat dan investor tentunya dilengkapi dengan perencanaan yang matang. Sesuai dengan teori yang ditulis oleh Charles R. Berger dalam (Budyatna, 2018: 87). Teori perencanaan komunikasi berusaha menjelaskan bagaimana individu tiba pada suatu pemahaman pada tindakan dan pembicaraan terhadap satu sama lain dengan tujuan yang diarahkan, dan bagaimana individu menghasilkan tindakan dan pembicaraan yang memungkinkan mereka untuk mencapai tujuan yang diharapkan. Seperti yang diungkapkan dalam asumsi metateorisnya, teori perencanaan berorientasi pada postpositivist dan menggambarkan tradisi realisme kognitif, sesuai dengan penelitian penulis yang menggunakan paradigma post-positivist.

Peneliti menggunakan 8 langkah komunikasi lingkungan melalui penelitian terdahulu yang ditemukan dari Wahyudin (2017:132)

1. Menganalisis situasi dan masalah yang terjadi.

2. Melakukan analisis pada pihak/pelaku yang terlibat pada kasus perusakan lingkungan.

3. Komunikasi untuk meningkatkan pengetahuan dan mempengaruhi perilaku masyarakat.
4. Mengembangkan analisis strategi komunikasi DLH.

5. Memotivasi dan memobilisir masyarakat Kawasan Wisata Mandeh.

6. Pemilihan media yang digunakan.

7. Penyebaran melalui media dan implementasinya.

8. Proses dokumentasi, monitoring, dan evaluasi dari DLH.

Sehingga dapat disimpulkan bahwa komunikasi lingkungan adalah strategi dan perencanaan mengenai lingkungan oleh pemerintah atau pemilik kepentingan kepada masyarakat, jajaran pemerintah, investor, dan industri sehingga menimbulkan kesadaran akan lingkungan secara bersama. Komunikasi yang efektif tentunya dapat menjadikan Pemerintah Kabupaten Pesisir Selatan memperoleh hal yang diharapkan dalam memperbaiki dan mempertahankan keindahan lingkungan di Kawasan Wisata Mandeh. Selain hal tersebut komunikasi juga memiliki fungsi sebagai potensi yang dapat digunakan untuk memenuhi tujuan-tujuan tertentu. Pada penelitian ini, penulis menggunakan 8 langkah dari 3 stage komunikasi lingkungan di atas, akan dijadikan rujukan sebagai dasar pengumpulan data lapangan pada penelitian ini.

\section{Proses Komunikasi Lingkungan yang Diterapkan DLH Dalam Pencegahan Kerusakan Lingkungan di Kawasan Wisata Mandeh}

\section{a. Menganalisis situasi dan masalah}

Proyek yang saat ini menjadi kasus di Kawasan Wisata Mandeh saat ini ada beberapa yang belum ada yang memiliki 
izin lingkungan. Adanya unsur kesengajaan dari pelaku karena ingin menghemat biaya dan mempersingkat waktu sehingga mengabaikan pengurusan izinkepemerintah setempat. Ketidakpedulian investor atau pemborong dengan lingkungan Kawasan Mandeh, membuang material jalan atau bangunan yang sedang dibangun ke laut tanpa mempertimbangkan apa yang akan rusak tepian laut akibat timbunan tersebut. Melakukan pembakaran dalam pembukaan lahan juga masih dijadikan kebiasaan. Pembabatan hutan mangrove untuk membuka lahan dan dermaga kapal. Selain itu juga membabat hutan lindung untuk mendirikan bangunan seperti resort atau rumah singgah.

\section{b. Melakukan analisis pada pihak/pelaku} yang terlibat pada kasus

Oknum perusakan kebanyakan berdalih bahwa mereka tidak mengetahui tentang lahan yang tidak boleh dilakukan pembangunan, namun hal ini sebenarnya adalah kelalaian oknum sendiri bahwa peta atau zona Kawasan Wisata Mandeh sudah tersedia di kantor Wali Nagari dan Kantor Camat setempat sehingga ini dapat dikatakan kesalahan yang disengaja. Ditambah lagi dengan melakukan penimbunan mangrove di laut dengan tanah perbukitan yang beralasan

Ketidaktahuan bahwa lahan milik pelaku merupakan kawasan hutan lindung, namun mangrove sudah lebih dulu dibabat dan ditimbun. Pembakaran lahan, yang beralasan awalnya hanya membakar tumpukan rumput dan ranting akhirnya menyebar hampir 1 ha di sekitar bukit tersebut. Pihak pelaku yang memiliki tanah juga ada yang tidak terima karena merasa memiliki hak penuh atas tanah yang dibeli. Hal ini terjadi disebabkan mereka tidak mengetahui bahwa zona tanah yang dimiliki tidak tepat untuk membangun bangunan permanen yang akan merusak lingkungan. Terdapat 11 proyek pembangunan di Kawasan Wisata Mandeh yang belum memiliki izin lingkungan, diantaranya seperti pada tabel 1:

\begin{tabular}{|clc|}
\hline No & \multicolumn{1}{c}{ Lokasi } & Belum Izin \\
\hline 1 & Labuhan Sundai & 1 \\
\hline 2 & Sungai Pinang & 3 \\
\hline 3 & Sungai Nyalo & 1 \\
\hline 4 & Pulau Pamutusan & 1 \\
\hline 5 & Pulau Kapo-Kapo & 1 \\
\hline 6 & Pulau Cubadak & 1 \\
\hline 7 & Pulau Setan & 1 \\
\hline 8 & Sikuai & 2 \\
\hline
\end{tabular}

Tabel 1.

Proyek Pembangunan Belum Ada Izin Lingkungan

c. Komunikasi untuk Meningkatkan

Pengetahuan dan Mempengaruhi Perilaku

Komunikasi langsung pada masyarakat, dengan edukasi cara membuka lahan yang benar. Memberikan kesadaran agar tidak melakukan pemboman ikan. Mengajak nelayan memanfaatkan rumah pribadi sebagai homestay. Hal ini dapat membengaruhi perilaku masyarakat yang saat ini sudah tidak lagi melakukan pengeboman ikan dan perusakan karang, karena masyarakat mengaku sulit mendapatkan ikan dalam rentan waktu tertentu dan melihat air keruh sepanjang pantai tentu tidak enak dilihat, untuk karang mereka 
sudah mau ikut dalam program pemerintah dalam melakukan transplantasi karang, sehingga karang terus tumbuh dan memperbaharui jenisnya.

Masyarakat juga tidak mau lagi memotong mangrove untuk keperluan rumah dan sampan, karena sudah mendapat himbauan mengenai hukuman yang akan didapatkan jika merusak mangrove. Karena mangrove yang tumbuh di sekitar pantai merupakan hasil yang ditanam oleh pemerintah dan masyarakat sebelumnya untuk menyelamatkan pantai jika terjadi nantinya bencana.

\section{d. Pengembangan Strategi Komunikasi}

Terdapat dua alasan komunikasi harus menggunakan strategi, pertama karena pesan yang kita sampaikan tidak hanya sampai terkirim melainkan diterima, kedua agar mendapatkan respon yang diinginkan, sehingga taktik dan strategi meruapakan langkah untuk melaksanakan perencanaan (Kalianda, 2018:4).

DLH sendiri melakukan proses awal dengan mengadakan rapat dan pertemuan internal guna menyatukan persepsi satu sama lain dengan anggota. Komunikasi lingkungan harus memberikan praktek penyiaran komunitas, jurnalisme pembangunan, komunikasi pendidikan dan pemasaran sosial. Serta menekankan pada proses enkulturasi dengan penggunaan komunikasi adat, media populer, penyadaran, dan mobilisasi sosial (Flor dan Cangara, 2018: 27). Penulis menemukan model untuk melakukan analisis strategi komunikasi lingkungan untuk DLH agar bisa diterapkan seperti gambar berikut:

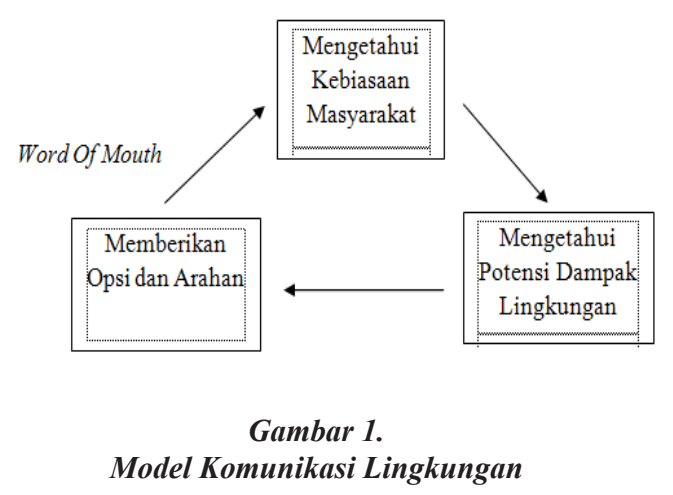

Gambar 1 dapat diterapkan oleh DLH untuk upaya komunikasi yang efektif dalam pencegahan kerusakan lingkungan pada Kawasan Wisata Mandeh. Analisis strategi komunikasi dengan mengetahui kebiasaan masyarakat yang sering membakar ketika akan membuka lahan baru, menimbun mangrove, pengeboman ikan dan karang. Hal ini tentu harus diperbaiki dengan cara yang benar. Pakar lingkungan menganggap alam dan budaya saling bahu membahu dalam berevolusi, sehingga salah satu strategi terbaik dalam komunikasi lingkungan adalah pemanfaatan budaya asli (Flor dan Cangara, 2018: 5). Lalu mengetahui potensi dampak lingkungan, DLH harus mengetahui kegiatan proyek apa saja yang memiliki potensi terjadinya kerusakan lingkungan nantinya, tidak hanya berpatokan pada proyek besar saja melainkan pada masyrakat setempat. Dengan begini DLH dapat memberikan opsi dan arahan penjelasan melalui komunikasi bagaimana solusi yang benar, seperti menangkap ikan tidak dengan bom melainkan dengan jala dan 'pukek', lalu melakukan transplantasi karang yang digunakan untuk cenderamata sehingga 
tidak harus merusak karang yang aslinya. Selanjutnya adanya word of mouth (WOM) yang tidak disengaja membuat masyarakat membicarakan hasil komunikasi dari DLH ke warga lain yang tidak sempat mengikuti sosialiasasi, hal tersebut berantai dan akan tersampaikan terus menerus sehingga dapat menimbulkan kepercayaan karena berasal dari orang yang mereka kenal, merujuk pada buku Kotler dan (Keller, 2009: 512) dan (Silverman, 2009: 26). Menentukan tujuan kegiatan, menentukan kegiatan DLH berupa sosialisasi, pembinaan masyarakat, pelatihan kuliner untuk ibu-ibu rumah tangga, FGD dengan mengundang beberapa pengusaha, pejabat nagari dan masyarakat, atau bahkan terjun langsung ke lapangan untuk melakukan praktek bersama masyarakat seperti menanam bibit mangrove, lalu menanam 10.000 pohon di Bukit Paku, dan pembersihan pantai secara bersama.

\section{e. Memotivasi dan Memobilisir Masyarakat}

Motivasi sebagai dorongan pada masyarakat untuk memperhatikan lingkungan dalam aktivitas sehari-hari sangat dibutuhkan, karena kebanyakan dari mereka sebelumnya belum mengetahui hal tersebut, mana yang boleh dan tidak boleh. Hanya saja masyarakat berpatokan pada kebiasaan yang dilakukan turun temurun.

Memobilisir masyarakat yang dilakukan DLH dengan mengirimkan surat pada Wali Nagari bahwa DLH akan melakukan sosialisasi terkait dengan isu lingkungan, lalu nantinya Wali Nagari membuat surat undangan untuk tokoh nagari lainnya, selanjutnya dibagikan ke masyarakat sehingga masyarakat akan datang. DLH memberikan motivasi dan memobilisasi masyarakat dengan cara sosialisasi, baik sosialisasi dari pemerintah maupun saat musrembang dimana masyarakat dikumpulkan di darmaga Carocok Tarusan. Saat sosialisasi selalu menghadirkan sekitar 150 orang masyarakat dan perangkat nagari.

Melakukan FGD dengan mengundang seluruh pengusaha, diselenggarakan masalah IPLC (Izin Pengelolaan Limbah Cair), diundang para pengusaha industri yang akan mempunyai dampak dari usahanya tersebut. Selain kegiatan dari DLH, nagari juga terkadang berinisiatif mengundang pemerintah untuk memberikan sosialisasi pada masyarakat disana agar mereka mengerti bagian hutan mana yang kayunya boleh diambil untuk keperluan melaut, mana yang termasuk hutan lindung, dan apa yang tidak boleh dilakukan pada lingkungan dan seharusnya bagaimana harus bertindak. Mendirikan kelompok pemerhati lingkungan atau komunitas cinta lingkungan, kelompok ini yang dibina untuk ikut mengajak masyarakat lain untuk berkala membersihkan pantai.

Melakukan pembinaan pada sekolahsekolah Adiwiyata diPesisirSelatan Proklim (Program Kampung Iklim) yang dilakukan untuk mempersiapkan masyarakat dengan keadaan mendadak nanti yang akan terjadi seperti saat kemarau, masyarakat sudah memiliki cadangan air yang sudah ditampung melalui lubang resapan saat musim hujan. Kegiatan semacam ini dapat 
menguntungkan masyarakat sehingga tidak kesulitan jika hujan tidak kunjung turun.

\section{f. Pemilihan Media yang Digunakan}

Pada penelitian terdahulu (Herutomo, 2013: 2) menyebutkan dari hasil penelitiannya bahwa komunikasi lingkungan melalui media massa cetak, elektronik dan media sosial dengan pemberitaan yang investigatif tentang masalah kehutanan dapat menumbuhkan kesadaran dan partisipasi masyarakat dalam turut mengelola hutan berkelanjutan.

Dalam penelilitian ini juga menunjukkan bahwa media dimanfaatkan oleh DLH seperti Painan Radio dan Langkisau Radio, TV lokal pemerintah Pesisir Selatan yaitu SPM TV, mobil keliling diskominfo, spanduk atau baliho yang dipasang pada tempat-tempat strategis yang mudah dilihat oleh masyarakat. Selanjutnya yaitu menggunakan surat edaran untuk memberikan informasi pada kecamatan dan nagari melalui camat dan wali nagari, Berita melalui koran yang biasanya adalah statement dari Bupati yang sebelumnya sudah brifing dulu dengan DLH. Papan/ Plang pelarangan, yang digunakan sebagai himbauan untuk tidak melakukan kegiatan pembangunan tanpa izin, pembakaran hutan, dilarang merusak terumbu karang, dilarang merusak mangrove. Plang nya diletakan di lokasi yang akan melakukan kegiatan pembangunan, sehingga semua proyek yang dinyatakan belum ada izin lingkungan tidak dapat melanjutkan pembangunan. Media Online: Broadcast WhatsApp Group dari DLH disampaikan ke
WhatsApp Group instansi lain, Facebook pribadi.

g. Penyebaran Melalui Media Dan Implementasinya

Penyebaran melalui media yang digunakan dirasa efektif untuk menjangkau masyarakat, namun untuk masyarakat pedalaman tentu saja implementasi dilakukan DLH dengan langsung mendatangi dan melakukan aktivitas bersama dapat menambah pengetahuan penduduk setempat.

Masyarakat menyambut baik, karena mereka yang awalnya tidak tau dan kurang pengetahuan sekarang menjadi lebih mengerti apa yang harus dilakukan dan apa yang tidak boleh. Adanya hukum sosial dan efek jera, dimana oknum yang merusak lingkungan diproses hukum sehingga masyarakat lain tidak mau mengulangi kesalahan yang sama untuk merusak lingkungan lagi dalam model apapun, karena sebelumnya sudah ada oknum yang diproses hukum dengan pidana 3 tahun penjara. Dengan sosialisasi dan pembinaan, jumlah pengeboman ikan dan perusak terumbu karang sudah tidak ada lagi dalam dua tahun terakhir. Masyarakat banyak menggunakan cara lama dengan jala atau 'pukek'.

Melalui pembinaan dan praktek langsung, masyarakat tidak lagi merusak dan mengambil terumbu karang asli untuk dijadikan cenderamata, melainkan dengan transplantasi terumbu karang dapat menjadi pengganti. Sehingga karang asli dapat tetap lestari. Pelatihan kuliner membuat beberapa ibu-ibu akhirnya membuat 
warung makan disekitar rumah untuk para pengunjung yang datang sehingga meningkatkan ekonomi masyarakat. Kesadaran masyarakat mencapai $70 \%$. Untuk investor/pengusaha, lebih pada tekanan langsung jika tidak melakukan sesuai dengan instruksi. Masyarakat sudah berani melakukan pengaduan pada DLH jika terdapat proyek pembangunan baru, berinisiatif menanyakan proyek tersebut sudah ada dokumen atau belum.

\section{h. Proses Dokumentasi, Monitoring, dan} Evaluasi

Tahap Monitoring: pengawasan dilakukan per-triwulan atau enam bulan sekali, proyek sesuai atau tidak dengan dokumen pengolahan limbah dan dampak lingkungan yang diajukannya, jika pengujian menunjukan adanya ketidaksesuaian maka DLH wajib mencabut izin karena limbah tidak dikelola dengan benar.

Tahap Evaluasi: pengkajian ulang bagaimana keadaan di lapangan ketika kegiatan dilaksanakan, respon masyarakat saat kegiatan berlangsung, kekurangan apa saja yang terdapat dalam kegiatan, membahas bagaimana seharusnya yang dilakukan pada kagiatan yang akan datang, ex: kegiatan ditambah dengan games, laporan kebijakan lalu inventarisasi terhadap kegiatan.

\section{KESIMPULAN}

Kesimpulan yang dapat diambil dari penelitian ini adalah dengan menggunakan 8 langkah komunikasi lingkungan yang mendapatkan strategi perencanaan dengan mengetahui kebiasaan masyarakat, melihat potensi yang akan ditimbulkan dari dampak lingkungan dan memberikan arahan melalui kegiatan komunikasi. Kegiatan yang dilakukan oleh DLH adalah dengan sosialisasi, FGD yang melibatkan akademisi universitas, pemerintah dan masyarakat serta investor, selanjutnya melalui pembinaan pada masyarakat, pelatihan dengan praktek langsung, dan membangun komunitas pecinta lingkungan di kalangan masyarakat setempat. komunikasi yang disebarkan melalui media massa seperti: melalui SPM TV, Painan Radio dan Langkisau FM, memasang baliho di tempat strategis sehingga mudah dilihat orang, plang pelarangan untuk proyek yang tidak boleh melakukan kegiatan pembangunan karena melanggar zonasi hutan, surat edaran yang diberikan pada pejabat daerah, lalu berita koran, untuk media online DLH memanfaatkan website DLH, facebook pribadi dan WhatsApp grup.

Dinas Lingkungan Hidup sebagai komunikator melakukan sosialisasi, demo mengenai lingkungan disekitar Kawasan Mandeh, mengajak masyarakat ikut andil dalam pelestarian lingkungan, memberikan gambaran yang jelas pada investor dan masyarakat daerah mana saja yang boleh melakukan pembangunan dan yang tidak boleh. Menjadikan masyarakat sekitar sebagai penggiat pariwisata berkelanjutan yang menghargai alam dan lingkungan saat ini, sehingga Kawasan Wisata Mandeh tetap indah sebagaimana yang diketahui masyarakat di luar sana. Komunikasi yang efektif tentu memberikan efek sesuai dengan yang diinginkan oleh komunikator, Dinas lingkungan Hidup dapat melakukan Focus Grup Discusion 
(FGD) dengan melibatkan masyarakat, investor, pemerintah lain seperti Dinas Kehutanan dan Lingkungan Hidup provinsi, para penggiat wisata, dan wartawan. Hal ini dapat memperjelas komunikasi dari semua pihak bagaimana menjadikan pariwisata di Kawasan Mandeh tetap indah tanpa kerusakan lingkungan.

\section{DAFTAR PUSTAKA}

Afrizal. 2014. Metode Penelitian Kualitatif Sebuah Upaya Mendukung Penggunaan Penelitian Kualitatif Dalam Berbagai Disiplin Ilmu. Jakarta: Rajagrafindo Persada.

Budyatna. 2015. Teori-teori Komunikasi Antar Pribadi. Jakarta: Prenada Media.

Bungin, Burhan. 2014. Penelitian Kualitatif edisi kedua. Jakarta: Preanada Media Group.

Cox, Robert. 2010. Environmental Communication and Public Sphere Second Edition. USA: Sage Publications.

Creswell, John W. 2013. Research Design Pendekatan Kualitatif, Kuantitatif, dan Mixed. Yogyakarta: Pustaka Pelajar.

Emzir. 2010. Analisis Data: Metodologi Penelitian Kualitatif. Jakarta. Rajawali Pers.

Flor, Alexander \& Havied Cangara. 2018. Котиnikasi Lingkungan; Penganganan KasusKasus Lingkungan Melalui Strategi Komunikasi. Jakarta: Prenadamedia Group.
Herutomo, Christo. 2013. Komunikasi Lingkungan Dalam Mengembangkan Hutan Berkelanjutan. Jurnal Actadiurna Volume 9 Nomor 2 2013: 37 - 48

Kalianda, Deri. 2018. Strategi Komunikasi Dinas Lingkungan Hidup (DLH) Dalam Mengimplementasikan Program Green City Di Kota Teluk Kuantan Kabupaten Kuantan Singingi. JOM FISIP voL. 5 No. 1-April 2018: 1 - 12.

Kotler dan Keller. 2009. Managemen Pemasaran Jilid 1. Jakarta: Erlangga.

Silverman, George. 2009. The Secret of Word Of Mouth Marketing: How to Trigger Exponential Sales Through Run Away Word Of Mouth. USA: AMA COM.

Soemarwoto, Otto. 2014. Analisis Mengenai Dampak Lingkungan. Yogyakarta: Gadjah Mada University Press.

Sugiyono. 2017. Memahami Penelitian Kualitatif. Bandung: Alfabeta.

----------. 2017. Metode Penelitian Kualitatif. Bandung: Alfabeta.

Wahyudin, Uud. 2017. Strategi Komunikasi Lingkungan Dalam Membangun Kepedulian Masyarakat Terhadap Lingkungan. Jurnal Common Volume 1 Nomor 2 Desember 2017: 130 - 134.

Yenrizal.2017.Lestarikan Bumi dengan Komunikasi Lingkungan. Yogyakarta: Deepublish. 
108 | Komunikasi, Vol. XIII No. 02, September 2019: 97-108 